Research Paper

\title{
Biological Function of Ribosomal Protein L10 on Cell Behavior in Human Epithelial Ovarian Cancer
}

\author{
Jimin Shi ${ }^{*}$, Lingyun Zhang ${ }^{1,2 *}$, Daibing Zhou ${ }^{1,2}$, Jinguo Zhang1,2, Qunbo Lin ${ }^{1,2}$, Wencai Guan ${ }^{1}$, Jihong \\ Zhang, Weimin Ren ${ }^{1,2}$, and Guoxiong $\mathrm{Xu}^{1,2}{ }^{\mathrm{W}}$ \\ 1. Center Laboratory, Jinshan Hospital, Fudan University, Shanghai 201508, China; \\ 2. Department of Oncology, Shanghai Medical College, Fudan University, Shanghai 200032, China. \\ * These authors contributed equally to this work. \\ $\square$ Corresponding author: Guoxiong Xu, MD, PhD. Scientist, Professor of Oncology, Center Laboratory, Jinshan Hospital, Fudan University, 1508 Longhang \\ Road, Shanghai 201508, P.R. China. Tel: +86-21-34189990; Fax: +86-21-57039502; Email: guoxiong.xu@fudan.edu.cn \\ (c) Ivyspring International Publisher. This is an open access article distributed under the terms of the Creative Commons Attribution (CC BY-NC) license \\ (https://creativecommons.org/licenses/by-nc/4.0/). See http://ivyspring.com/terms for full terms and conditions.
}

Received: 2017.06.25; Accepted: 2017.12.29; Published: 2018.02.06

\begin{abstract}
Ribosomal protein L10 (RPL10) is one of large ribosomal proteins and plays a role in Wilms' tumor and premature ovarian failure. However, the function of RPL10 in human epithelial ovarian cancer (EOC) remains unknown. The purpose of this study was to examine the expression level and function of RPL10 in EOC. RPL10 protein expression was detected by immunohistochemistry and Western blot. The association RPL10 expression with clinical features was analyzed. Loss-offunction and gain-of-function approaches were applied in cellular assays, including cell viability, migration, invasion, and apoptosis. Our study demonstrated for the first time that RPL10 was upregulated in human EOC compared with normal ovarian tissues. Knockdown of RPL10 inhibited cell viability, migration, and invasion, and increased cell apoptosis. On the contrary, upregulation of RPL10 increased cell viability, migration, invasion, and decreased cell apoptosis. Furthermore, miR-143-3p regulated RPL10 expression. Our data indicate that RPL10 is a potential tissue biomarker of patients with EOC and may be a therapeutic target of ovarian cancer.
\end{abstract}

Key words: Cell biology; biomarker; ovarian cancer; QM, RPL10; therapeutic target

\section{Introduction}

Ribosomal protein L10 (RPL10), also known as QM and DXS648, encoded by a gene located at the X chromosome q28 and its molecular weight is about 24 $\mathrm{kDa}$. RPL10 belongs to a highly-conserved component of ribosome subunits from yeast to human [1] and is a component of the large ribosomal subunit (60S) $[2,3]$, which functions as a suppressor of Wilms' tumor through the regulation of an oncogenic transcriptional factor c-Jun $[4,5]$. It has been shown that RPL10 may take part in signal transduction pathways in different cell biological processes, such as cell proliferation, migration, and differentiation [6]. High RPL10 protein level was found during the progression and development of prostate cancer [7]. Mutations in the RPL10 gene was found in patients with autism and modulating disease mechanism [8,
9]. It also affects severe defects in brain formation and function [10]. Increasing evidence has shown that the RPL10 has an important immune function in animal organisms, such as spleen, heart, and brain [11-15]. It also has reported that RPL10 is overexpressed in ovary tissue of Penaeus monodon [16]. However, the mechanism of RPL10 dysregulation in ovarian cancer (OC) development remains unknown.

It has been shown that microRNA (miRNA, miR) plays important roles in the development, diagnosis, and treatment of OC $[17,18]$. During the investigation of microRNA (miRNA, miR) biomarkers in the serum, we found that several miRNAs were decreased in patients with OC, including miR-143-3p. Previous studies have shown that the expression level of $\mathrm{miR}-143-3 p$ is downregulated in many cancers, such 
OC $[19,20]$. Therefore, we speculate that miR-143-3p may be associated with RPL10 expression in OC.

Human epithelial ovarian cancer (EOC), derived from the epithelial cells of the ovary or fallopian tube, accounts for about $90 \%$ of OCs and mainly occurs in postmenopausal women. EOC is the most lethal gynecological malignancy because of the difficulty to detect it at an early stage [21]. Data from American Cancer Society (ACS) showed that the overall rate of female OC deaths is maintained $4-5 \%$ per annum in the past five years. Therefore, ideally we need to define the biomarker for the early detection of OC. We recently reported that cystatin B [22], beta-2-microglobulin [23], cytidine monophosphate kinase [24], and Pyridoxine-5'-phosphate oxidase [25] are candidate human ovarian tumor progression markers. In this study, we evaluated the expression level of RPL10 in human ovarian tumor tissues and in OC cell lines, unraveled the relationship between RPL10 expression and clinicopathological features of patients with OC, and demonstrated the biological function of RPL10 in OC cells.

\section{Material and Methods}

\section{Patients and ovarian tissue specimens}

All cases have been approved by the patients and the Ethics Committee of Jinshan Hospital. All patients and ovarian tissue specimens were collected from Jinshan Hospital, Fudan University. All patients in the clinic underwent cytoreductive surgery and had not received preoperative radiotherapy and chemotherapy. Approval for this study on human subjects was granted by the Ethics Committee of Jinshan Hospital, Fudan University. The ovarian tissue samples from 69 patients with ovarian tumor (20 benign cases, 18 borderline cases, and 31 malignant cases) from January 2005 to December 2014 were collected for this study. The normal ovaries from 18 patients with non-ovarian tumor were obtained by surgery and used as controls.

The ovarian tissue specimens were fixed in 10\% formalin and embedded in paraffin. Specimens were sectioned and stained with hematoxylin and eosin (H/E). The histological characteristics were determined by two pathologists at the Department of Pathology, Jinshan Hospital. The histological grade and stage were classified based on the current criteria of Tumor, Node, and Metastasis (TNM) classification method from the American Joint Committee on Cancer (AJCC) and the World Health Organization (WHO). Experienced gynecologists and pathologists made a final diagnosis according to the FIGO (International Federation of Gynecological Oncologists) system.

\section{Immunohistochemistry (IHC)}

Immunochemical staining was performed as described previously [26]. In brief, $4-\mu \mathrm{m}$ tissue was sectioned and baked at $60^{\circ} \mathrm{C}$ for $2 \mathrm{~h}$. The tissues were deparaffinized in xylene and rehydrated in descending grades of alcohols. For antigen retrieval, the sections were immersed in $0.1 \mathrm{M}$ sodium citrate buffer ( $\mathrm{pH}$ 6.0) and heated in a microwave oven at $100^{\circ} \mathrm{C}$ for $1.5 \mathrm{~min}$. Endogenous peroxide activity was quenched by $3 \%$ hydrogen peroxide in methanol for 15 min. After blocking with $10 \%$ normal goat serum (Maixin Bio, Fuzhou, Fujian, China) for $40 \mathrm{~min}$ at room temperature, the sections were incubated with a monoclonal rabbit anti-RPL10 antibody (1:100 dilution, Santa Cruz Biotechnology, Inc.) at $4^{\circ} \mathrm{C}$ overnight. The sections were then incubated with the biotinylated anti-rabbit secondary antibody (Maixin Bio) at room temperature for $1 \mathrm{~h}$. The signal was detected using a DAB Kit (Maixin Bio). Finally, the sections were counterstained with hematoxylin and photographed under a light microscope (BX43, OLYMPUS, Tokyo, Japan). A normal ovarian tissue without a primary antibody was used as a negative control. A brown color shown in the cytoplasm was considered as positive staining.

Immunoreactive staining was evaluated by two pathologists with consensus as described previously [22]. Briefly, the percentage of positive cells were scored as $0(0 \%$, no positive cells), 1 ( $\leq 25 \%$ positive cells), 2 (26-50\% positive cells), 3 (51-75\% positive cells), and 4 ( $>75 \%$ positive cells). The intensity of immunoreactive staining was scored as 0 (no staining), 1 (weak staining), 2 (moderate staining), and 3 (strong staining). The staining index (SI) was calculated by the sum of the positive extent and staining intensity. Finally, the cases were categorized based on the SI score 0-4 to be RPL10-negative and 5-7 to be RPL10-positive.

\section{Cell culture and RPL10-siRNA transfection}

Human serous ovarian cancer cell lines (OVCAR-3 and SK-OV-3) were purchased from American Type Culture Collection (ATCC, Manassas, VA, USA). OVCAR-3 cells were cultured in RPMI-1640 and SK-OV-3 cells were cultured in DMEM medium with $4.5 \mathrm{~g} / \mathrm{L}$ glucose (Corning, Mediatech Inc., Manassas, VA, USA), respectively, supplemented with $10 \%$ fetal bovine serum (FBS, Invitrogen, Carlsbad, CA, USA). Non-tumorous human ovarian surface epithelial cells (HOSEpiC, HOS) were obtained from Jennio Biotech Co., Ltd (Guangzhou, Guangdong, China) and cultured in RPMI-1640 medium (Corning) with 10\% FBS. Cells were maintained at $37^{\circ} \mathrm{C}$ in $5 \% \mathrm{CO}_{2}$ of the humidified atmosphere. For transient transfection, OVCAR-3 
cells were seeded in a six-well plate for $24 \mathrm{~h}$. After washing with Opti-MEM medium (Gibco, Thermo Fisher Scientific, Rockford, IL, USA), the cells were transfected with three RPL10-specific short interfering RNAs and a negative control siRNA (GenePharma Co., Ltd., Shanghai, China) (For sequences of siRNA, see Table 1) at a final concentration of $2 \mu \mathrm{g} /$ well for 6 $\mathrm{h}$ using X-tremeGENE siRNA Transfection Reagent (Roche Diagnostics, Indianapolis, IN, USA) as described by the manufacturer's instruction.

\section{Generation of RPL10-shRNA and RPL10-plasmid-expressing cells}

Human RPL10 short hairpin RNA (RPL10-shRNA,) was constructed with double-strand oligonucleotides corresponding to the target sequence of GCCCGAATTTGTGCCAATA and inserted into PHY-310 RNAi lentivirus containing green fluorescent protein (GFP) (hU6-MCS-CMV-ZsGreen 1-PGK-Puro, Hanyin Biotechnology Co., Ltd., Shanghai, China). Human RPL10 (NM_006013.4, length 645bp) plasmid (RPL10-plasmid,) was inserted into PHY-008 lentivirus (CMV-MCS-PGK-Puro, Hanyin Biotechnology Co., Ltd., Shanghai, China). The sense and antisense sequences of RPL10-shRNA and RPL10-plasmid were listed in Table 1. A control lentivirus with shRNA (Control) or plasmid (Vector) was also supplied by Hanyin Biotechnology.

Next, we generated the RPL10-shRNA or RPL10-plasmid expressing cells and their respective control cells. OVCAR-3 cells were seeded in six-well plate overnight and infected with RPL10-shRNA or RPL10-plasmid lentivirus at the concentration of 20 multiplicity of infection (MOI) and 15 MOI, respectively, with polybrene at a final concentration of $8 \mu \mathrm{g} / \mathrm{ml}$. After $24 \mathrm{~h}$, infection medium was replaced with fresh medium supplemented with 3 $\mu \mathrm{g} / \mathrm{ml}$ puromycin for killing non-infected cells. Fluorescence microscopy was used for examining the efficiency of RPL10-shRNA lentiviral transduction.
The expression of RPL10-shRNA and RPL10-plasmid at protein levels was detected by Western blot. RPL10-shRNA and RPL10-plasmid expressing cells at the fifth passage were used for the functional assays below.

\section{Measurement of cell viability}

RPL10-shRNA expressing cells, RPL10-plasmid expressing cells and control cells were seeded in 96-well plate at a density of $1 \times 10^{4} /$ well and cultured for 24,48 or $72 \mathrm{~h}$. Cell viability was detected by WST-1 assay (Roche Diagnostics, Indianapolis, IN, USA) according to the manufacturer's instruction. The signal in optical density (OD) was detected at 450 nm by a plate reader (BioTek Epoch, Winooski, VT, USA). Experiment was repeated at least three times.

\section{Cell migration and invasion assays}

Cell migration and invasion were measured using a transwell plate. For migration assay, cells were plated into 24-well transwell chamber containing a polycarbonate membrane with $6.5 \mathrm{~mm}$ in diameter and 8- $\mu \mathrm{m}$ in pore size (Costar Corning, New York, NY, USA). For invasion assay, the transwell chamber was coated with a Matrigel $(250 \mu \mathrm{g} / \mathrm{ml}$, BD Biosciences \#356234, Bedford, MA, USA). Briefly, cells were seeded into the upper chamber at a density of $5 \times 10^{4}$ cells/well with $100 \mu 1$ of RPMI- 1640 medium without serum, respectively. The lower chamber was filled with $600 \mu$ lof the same medium containing $10 \%$ FBS. After incubation for $36 \mathrm{~h}$ (migration) or $48 \mathrm{~h}$ (invasion), non-migrated or non-invasion cells were removed from the upper chamber gently. The migrated and invasion cells on the lower side of the membrane were fixed with $4 \%$ paraformaldehyde and stained with $5 \%$ crystal violet. Stained cells were photographed under a light microscope. Cell number was counted in three random fields. All experiments were repeated at least three times.

Table 1. Sequences of siRNA, shRNA, and plasmid

\begin{tabular}{|c|c|c|}
\hline Name & Sense $\left(5^{\prime} \rightarrow 3^{\prime}\right)$ & Antisense $\left(5^{\prime} \rightarrow 3^{\prime}\right)$ \\
\hline \multicolumn{3}{|l|}{ siRNA } \\
\hline Homo-RPL10-339 (S1) & CAUGGUGUCAGAUGAAUAUTT & AUAUUCAUCUGACACCAUGTT \\
\hline Homo-RPL10-388 (S2) & GCCCGAAUUUGUGCCAAUATT & UAUUGGCACAAAUUCGGGCTT \\
\hline Homo-RPL10-723 (S3) & GUCCACCUAUGUCUUUGUATT & UACAAAGACAUAGGUGGACTT \\
\hline C-siRNA & UUCUCCGAACGUGUCACGUTT & ACGUGACACGUUCGGAGAATT \\
\hline \multicolumn{3}{|l|}{ shRNA } \\
\hline RPL10-shRNA & $\begin{array}{l}\text { gatccGCCCGAATTTGTGCCAATATTCAAGAGATATTGGCAC } \\
\text { AAATTCGGGCTTTTTTg }\end{array}$ & $\begin{array}{l}\text { aattcAAAAAAGCCCGAATTTGTGCCAATATCTCTTGAATATTG } \\
\text { GCACAAATTCGGGCg }\end{array}$ \\
\hline \multicolumn{3}{|l|}{ Plasmid } \\
\hline RPL10-plasmid & CCGCTCGAGGCCACCATGGGCCGCCGCCCCGCC & $\begin{array}{l}\text { CGGGATCCTCACTTGTCGTCATCGTCCTTGTAGTCTGAGTGC } \\
\text { AGGGCCCGCCACTTGTCC }\end{array}$ \\
\hline
\end{tabular}

The numbers in homo-RPL10 $(339,388$, and 723) indicate the positions in RPL10 mRNA sequence (GenBank Accession: NM_006013). The low case indicates a linker. shRNA short hairpin RNA, siRNA small interfering RNA 


\section{Western blotting}

Cells and tissues were lysed in SDS lysis buffer with 1\% phenylmethylsulphonyl fluoride (Beyotime, Haimen, Jiangsu, China). Equal amount proteins were separated on $12 \%$ SDS-PAGE and transferred to a PVDF membrane (Millipore, Billerica, MA, USA). After blocking with 5\% non-fat milk in Tris-buffered saline with Tween 20 (TBS-T) for $1 \mathrm{~h}$, the membrane was incubated with a primary antibody at $4^{\circ} \mathrm{C}$ overnight and subsequently incubated with horseradish peroxidase-conjugated goat anti-rabbit or anti-mouse IgG (1:10000 dilution, Cell Signaling Technology, Inc., Danvers, MA, USA) for 1 hour at room temperature. The following primary antibodies were used: rabbit anti-RPL10 (1:2000 dilution, Abgent, Inc., San Diego, CA, USA) and mouse anti- $\beta$-actin (1:5000 dilution) (Cell Signaling Technology, Inc.). Signals were detected using Immobilon ${ }^{\mathrm{TM}}$ Western Chemiluminescent HRP Substrate (Millipore) and quantified using Tanon-4500 Gel Imaging System with GIS ID Analysis Software v4.1.5 (Tanon Science \& Technology Co., Ltd., Shanghai, China).

\section{Analysis of cell cycle and apoptosis by flow cytometry}

Cells were seeded in 6-well plates and cultured for $48 \mathrm{~h}$. For cell cycle assay, after trypsinization, the cells were washed with cold PBS twice at $1000 \mathrm{rpm}$ for 5 min each and fixed with cold $70 \%$ ethanol overnight. After washing cells with PBS three times, the pellet was resuspended in $500 \mu \mathrm{l}$ of propidium iodide (PI) solution in RNase staining buffer (PI/RNase Staining Buffer, BD Pharmingen, San Diego, CA, USA). After incubation at room temperature for $15 \mathrm{~min}, 10000$ cells were acquired by flow cytometry (Beckman Coulter, Inc., Brea, CA, USA). The results were analyzed by Wincycle software (Beckman Coulter) and presented as the percentage of cells in G0/G1, S, and G2/M phases. Apoptotic cells were detected by staining cells with annexin $\mathrm{V}$ conjugated with allophycocyanin (RPL10-shRNA) or fluorescein isothiocyanate (RPL10-plasmid) (Allophycocyanin, BD Pharmingen, BD Biosciences) and PI (BD Pharmingen). Briefly, after trypsinization, the cells were resuspended in $1 \mathrm{X}$ binding buffer at a density of $1 \times 10^{6}$ cells $/ \mathrm{ml}$. After transferring $100 \mu \mathrm{l}$ of cell suspension into a fresh tube, $5 \mu \mathrm{l}$ of APC Annexin V and/or $5 \mu \mathrm{l}$ of PI was added. The cells were incubated in the dark for $15 \mathrm{~min}$. After adding $400 \mu \mathrm{l}$ of $1 \mathrm{X}$ binding buffer to each tube, cell population was analyzed by flow cytometry within 1 hour.

\section{Transfection of miR-143 mimics/inhibitors}

After seeding at a density of $2 \times 10^{5}$ cells/well into 6-well plate and cultivation for $16 \mathrm{~h}$, OVCAR-3 cells were transfected with $50 \mathrm{nM}$ miR-143-3p mimics (UGAGAUGAAGCACUGUAGCUC) and miR-negative control (CTL, UCACAACCUCCUAGAAAGAGU AGA) or 150 nM miR-143-3p inhibitors (antimiR-143-3p, GAGCUACAGUGCUUCAUCUCA) and anti-miR-negative control (NC, UCUACUCUUUCUA GGAGGUUGUGA) (RiboBio Co., Ltd, Guangzhou, Guangdong, China), respectively, using X-treme GENE Transfection Reagent (Roche Applied Science). Protein was extracted $72 \mathrm{~h}$ post culture for Western blotting.

\section{Statistical analyses}

Data were analyzed using SPSS software (version 21.0 for Windows, Chicago, IL, USA). For comparison of RPL10 protein expression in ovarian tissue associated with the clinicopathological characteristics of patients, a Fisher's exact test or $\chi^{2}$ test was applied. For comparison between two groups of immunostaining scorings and treatment experiment, a Student $t$-test was applied. Results are shown as the mean \pm standard error of the mean (SEM). Significant difference was considered at the value of $\mathrm{P}<0.05$.

\section{Results}

\section{RPL10 protein is overexpressed in human epithelial ovarian cancer tissue}

IHC showed that RPL10 protein was overexpressed in human ovarian surface epithelial tumors (Fig. 1A). The immunoreactivity staining of RPL10 was weak in normal ovarian tissue and benign tumor, strong in borderline tumor and malignant tumors, including serous, mucinous, endometrioid, transitional cell, and clear cell malignant tumors. In a case of serous ovarian adenocarcinoma, we confirmed that the immunoreactivity staining of RPL10 was different between the histological types: weak staining in benign tissue and strong staining in borderline and malignant tissues (Fig. 1B). Based on the SI system, we categorized RPL10 expression into the positive and negative group. Statistical analyses showed that the positive rate of RPL10 protein expression was significantly higher in malignant tumor than in normal and benign tumor $(\mathrm{P}<0.05$; Fig. $1 C)$, while no difference was found between normal and benign tumor and between borderline and malignant tumors $(\mathrm{P}>0.05)$. The overexpression of RPL10 protein in serous ovarian tumors was also confirmed by Western blotting (Fig. 2). RPL10 protein was increased in borderline and malignant tumors compared with normal ovarian tissue $(\mathrm{P}<0.05)$ and benign ovarian tumor $(\mathrm{P}<0.01$; Fig. $2 \mathrm{~A}$ and $2 \mathrm{~B}$; $\mathrm{n}=3$ each). The overexpression of RPL10 in ovarian 
borderline and malignant tumors was also observed at the mRNA level (Fig. 2C; $n=3$ each). Furthermore, expression of RPL10 protein was higher in ovarian cancer cell lines (OVCAR-3) than in non-tumorous human ovarian surface epithelial cells line (HOS)
( $\mathrm{P}<0.05$; Fig. 2D and 2E). The expression of RPL10 protein was slightly higher, but not significant, in another OC cell line (SK-OV-3) compared with HOS cells $(\mathrm{P}>0.05, \mathrm{n}=3$; Fig. 2D and 2ED).

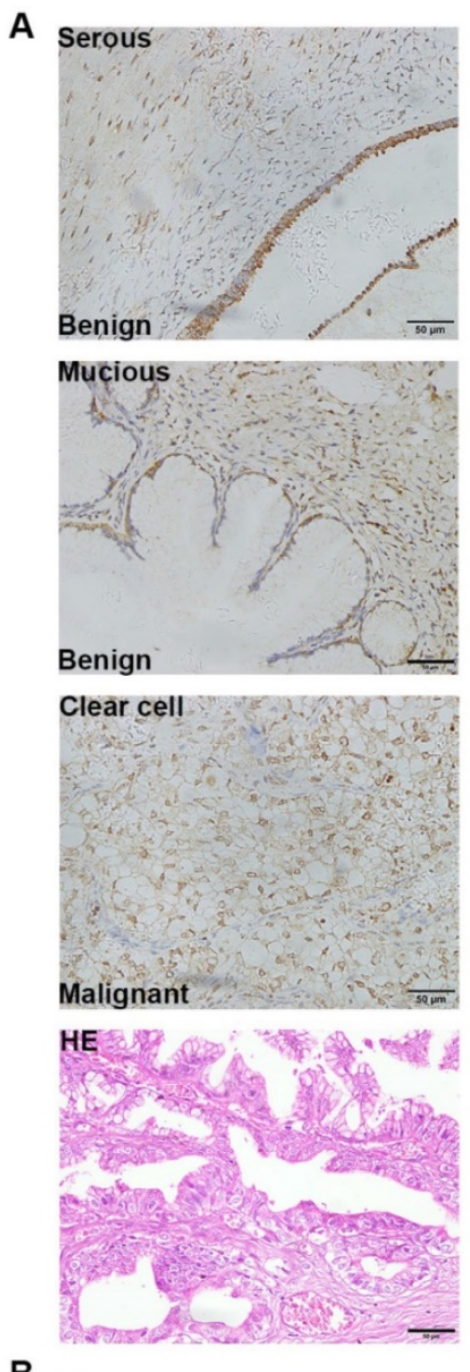

B

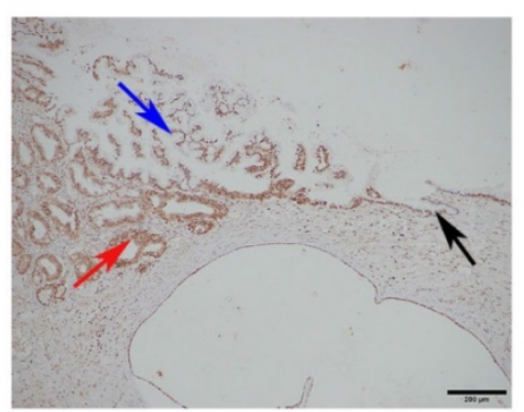

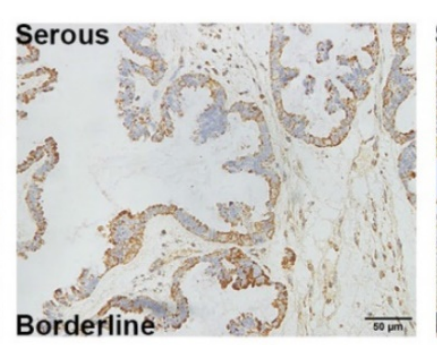
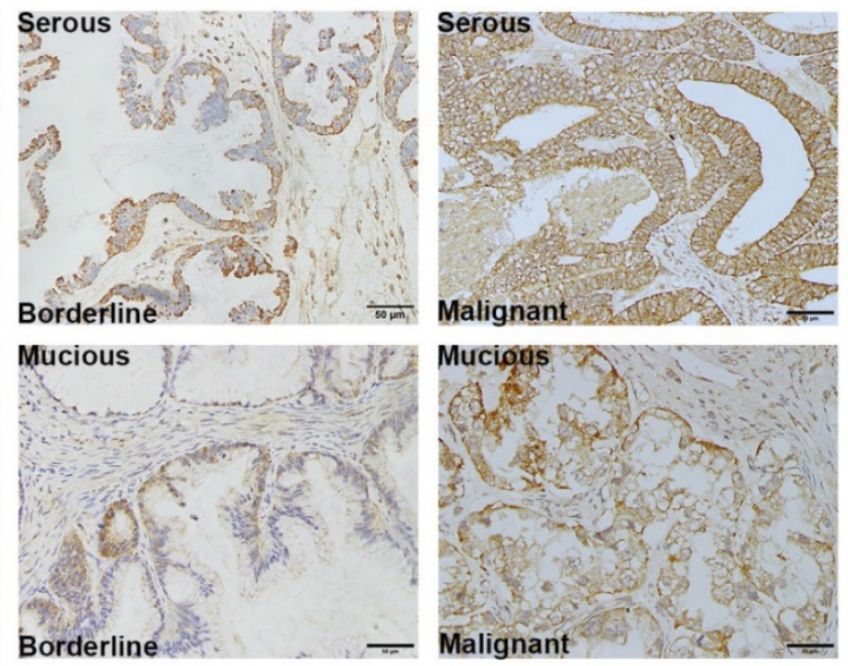

Transitional cell
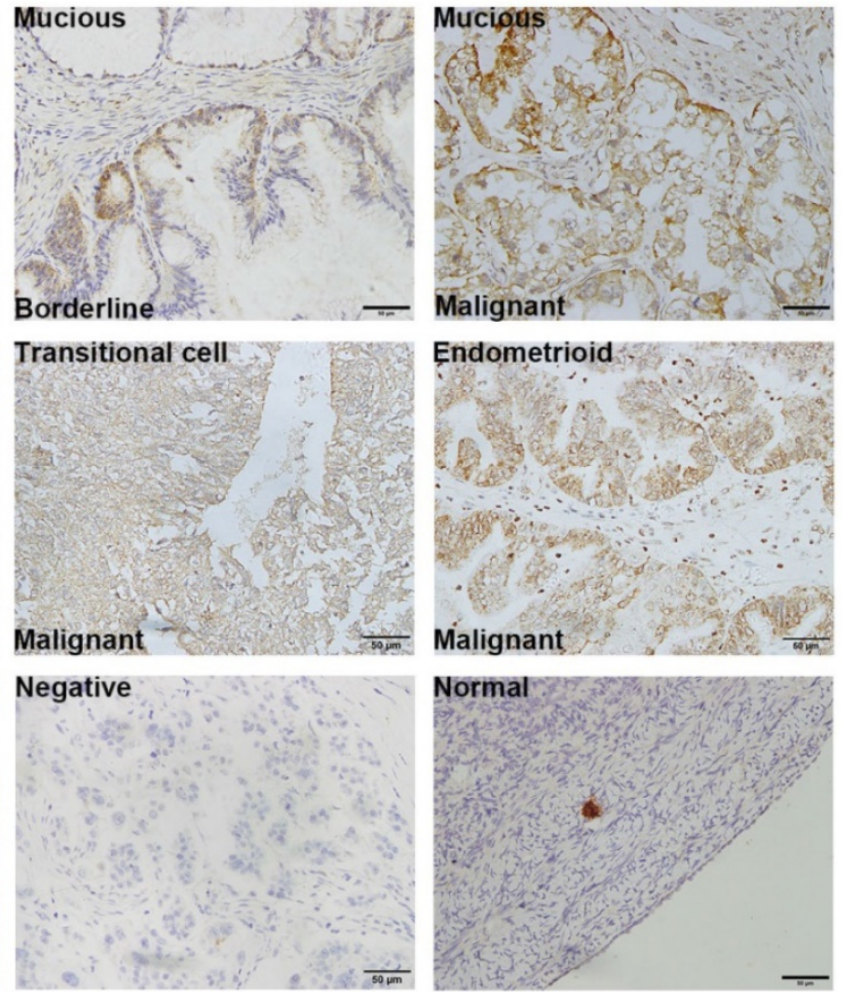

C
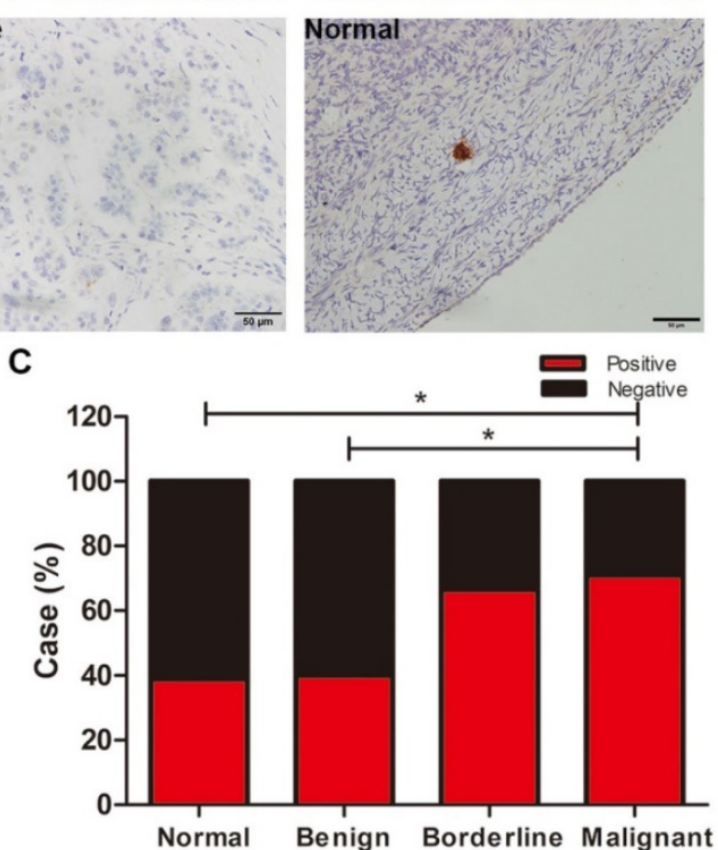

Figure 1. RPL10 expression in human ovarian tissues. (A) Immunohistochemistry staining of RPL10. Representative images of RPL10 expression in normal ovarian tissue, serous and mucinous benign, borderline, and malignant tumors, and clear cell, transitional cell, and endometrioid malignant tumors are shown. A brown color in epithelial cell is considered as a positive staining. Original magnification, $\times 400$. Scale bar, $50 \mu \mathrm{m}$. (B) Ovarian tissue of a patient with serous ovarian adenocarcinoma. Black arrow indicates benign tissue; blue arrow indicates borderline tissue; red arrow indicates malignant tissue. Original magnification, $\times 100$. Scale bar, $200 \mu \mathrm{m}$. (C) The case rate of RPL10 positivity and negativity. Positive vs. negative is shown: 7 vs. 11 in normal control (18 cases), 8 vs. 12 in benign tumor (20 cases), 12 vs. 6 in borderline tumor (18 cases) and 22 vs. 9 in malignant tumor (31 cases). A Fisher's exact test was applied for comparisons between two groups: normal vs. benign tumor $(\mathrm{P}=1.000)$, normal vs. borderline tumor $(\mathrm{P}=0.181)$, and normal vs. malignant tumor $(\mathrm{P}=0.038)$, benign tumor vs. borderline tumor $(\mathrm{P}=0.119)$, benign tumor vs. malignant tumor $(\mathrm{P}=0.042)$, and borderline tumor vs. malignant tumor $(\mathrm{P}=0.759)$. 
A

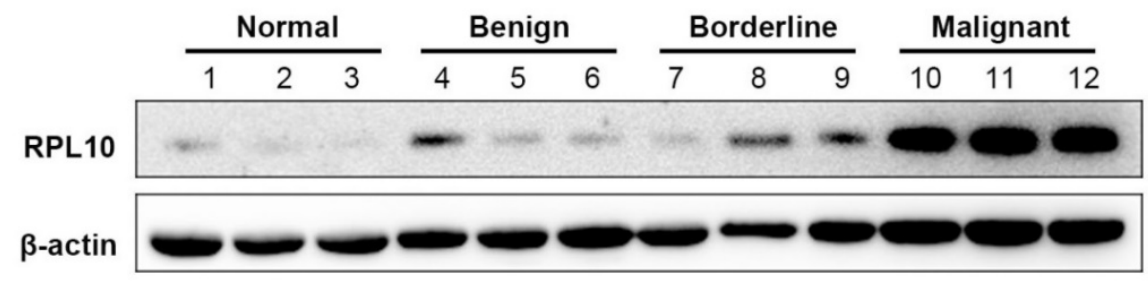

B
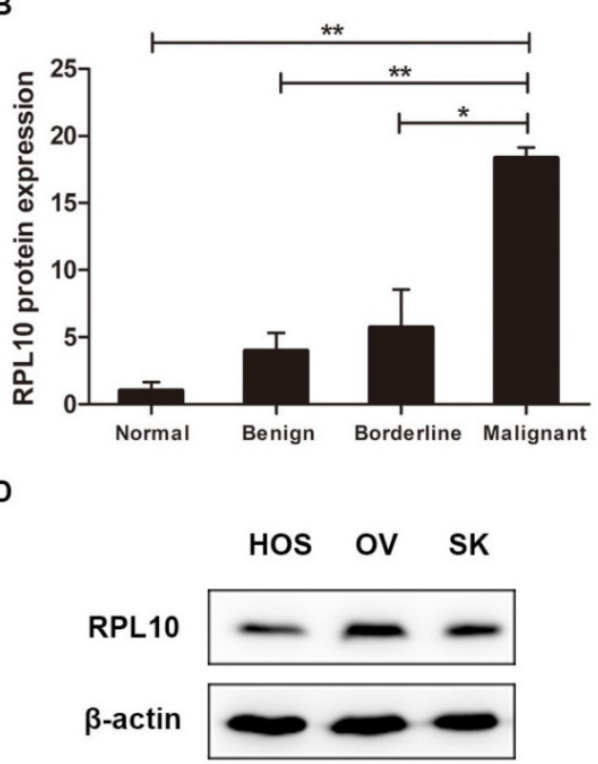

$\mathbf{F}$

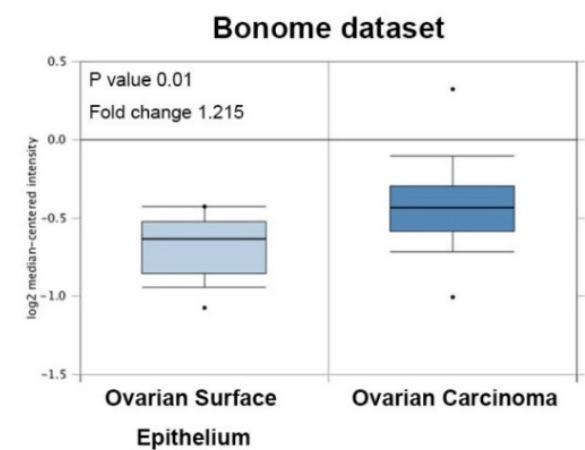

C

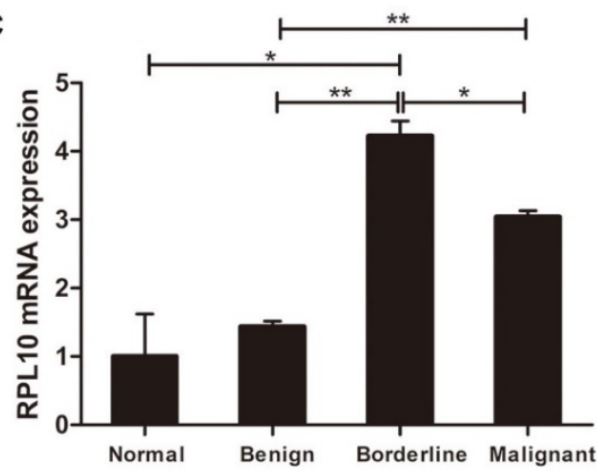

E

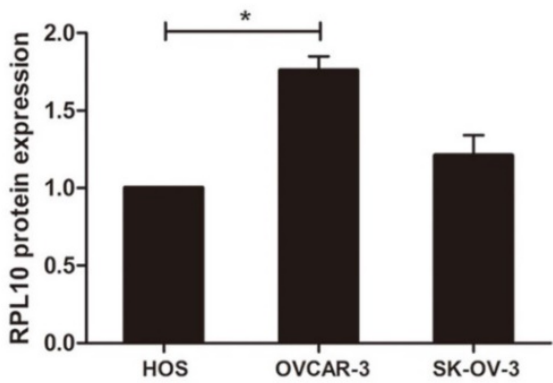

G

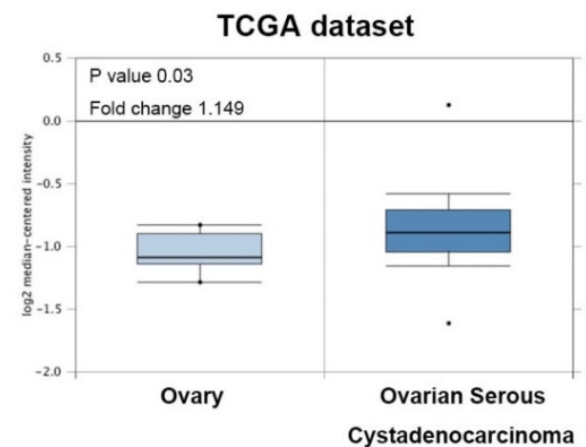

Figure 2. RPL10 expression in human ovarian tissues and cell lines. (A) RPL10 protein expression in normal ovarian tissue (case \#1-3) and ovarian serous benign (case \#4-6), borderline (case \#7-9), and malignant (case \#10-12) tumors was detected by Western blot using a specific antibody. (B) Semi-quantitative analysis after densitometry on the gels of (A). (C) RPL10 mRNA expression in normal ovarian tissue and ovarian serous tumors (benign, borderline, and malignant; $\mathrm{n}=3$ each type) was detected by qRT-PCR. (D) RPL10 protein expression was detected in HOS, OV, and SK cells by Western blot. (E) Semi-quantitative analysis after densitometry on the gels of $(E)(n=3)$. (F) RPL10 mRNA expression in ovarian carcinoma $(n=185)$ compared with normal ovarian surface epithelium (OSE, $n=10)$ in the microarray datasets of Bonome from Oncomine databases. (G) RPL10 mRNA expression in ovarian serous adenocarcinoma ( $n=586)$ compared with ovary ( $n=8)$ in the TCGA datasets. *, P<0.05; **, P<0.01. RPLIO ribosomal protein L10; HOS human ovarian surface epithelial cell line; OV OVCAR-3 cell line; SK SK-OV-3 cell line.

Next, we examined whether the expression of RPL10 is associated with the clinicopathological features of patients with EOC. Multiple comparisons showed that RPL10 expression was not associated with age, histological type, differentiation, lymph node metastasis, and clinical stage in patients with EOC ( $>>0.05$; Table 2).

By analyzing public datasets, we found that the high level of RPL10 mRNA expression was observed in ovarian carcinoma $(n=185)$ compared with normal ovarian surface epithelium (OSE, $n=10$ ) in the microarray datasets of Bonome from Oncomine databases (www.oncomine.org) $(\mathrm{P}=0.01$; Fig. $2 \mathrm{~F})$. The high level of RPL10 mRNA expression was also found in ovarian serous adenocarcinoma $(\mathrm{n}=586)$ compared with ovary $(n=8)$ in the TCGA datasets $(P=0.03$; Fig. $2 \mathrm{G}$ ). These data further confirm the overexpression of RPL10 in OC. 
Table 2. Association of RPL10 expression with clinicopathological features of patients with epithelial ovarian cancer

\begin{tabular}{|c|c|c|c|c|}
\hline \multirow[b]{2}{*}{ Clinicopathological features } & \multirow[b]{2}{*}{$\mathbf{n}$} & \multicolumn{2}{|c|}{ RPL10 expression } & \multirow[b]{2}{*}{ P-value } \\
\hline & & Positive (\%) & Negative (\%) & \\
\hline Age & & & & $1.000^{a}$ \\
\hline$\leq 45$ & 5 & 4 & 1 & \\
\hline$>45$ & 26 & 18 & 8 & \\
\hline Histological type & & & & $0.645^{b}$ \\
\hline Serous tumor & 16 & 11 & 5 & \\
\hline Mucinous tumor & 4 & 3 & 1 & \\
\hline Clear cell tumor & 7 & 6 & 1 & \\
\hline Others* & 4 & 2 & 2 & \\
\hline Differentiation & & & & $0.638^{b}$ \\
\hline Well & 7 & 4 & 3 & \\
\hline Moderate & 17 & 13 & 4 & \\
\hline Pool & 7 & 5 & 2 & \\
\hline Lymph node metastasis & & & & $0.693^{a}$ \\
\hline NO & 17 & 13 & 4 & \\
\hline YES & 14 & 9 & 5 & \\
\hline FIGO stage & & & & $0.253^{a}$ \\
\hline I-II & 19 & 15 & 4 & \\
\hline III-IV & 12 & 7 & 5 & \\
\hline
\end{tabular}

The expression of RPL10 was detected in ovarian malignant tumors by immunohistochemistry. For comparisons of RPL10 expression associated with age, lymph node metastasis, and FIGO stages, a Fisher's exact test was applied (a). For comparisons of RPL10 expression associated with histological types and

differentiation, a $\chi 2$ test was applied $\left({ }^{b}\right)$. n, number of cases; Positive, positive expression; Negative, negative expression; FIGO, International Federation of Gynecological Oncologists. *, 2 cases of transitional cell carcinoma and 2 cases of endometrial cancer.

\section{RPL10 suppression decreases the viability of ovarian cancer cell}

Since RPL10 protein was overexpressed in EOC and was higher in OVCAR-3 cell line, a loss-of-function approach was used to evaluate the functional significance of RPL10 in this cell line. First, RPL10 expression was knocked down with using siRNAs in OVCAR-3 cells. Western blot confirmed the efficacy of RPL10 silence at the protein level in cells transfected with RPL10-siRNA compared with cells transfected with negative control siRNA (C-siRNA) (Fig. 3A and 3B). To construct RPL10-shRNA lentivirus, we chose S2 which showed the highest efficiency of knockdown among the three RPL10-siRNAs examined. OVCAR-3 cells were infected with RPL10-shRNA lentivirus containing GFP and the efficiency of the transduction of RPL10-shRNA was monitored by fluorescence microscopy. We found that the expression of GFP was relatively stable and nearly $100 \%$ cells were GFP-positive at the 5th passage of OVCAR-3, while there was no morphological change in RPL10-shRNA expressing cells (Fig. 3C). The knockdown of RPL10 protein was confirmed by Western blotting (Fig. 3D and 3E). Furthermore, knockdown of RPL10 affected
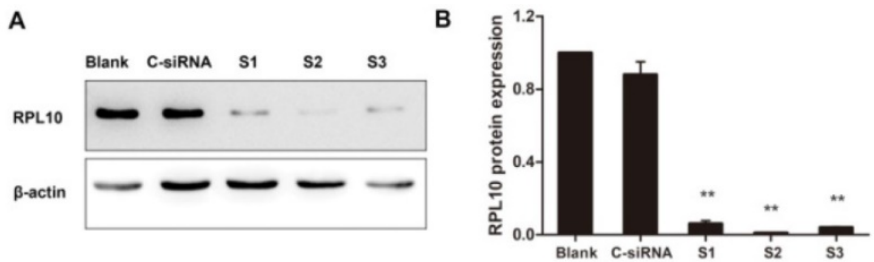

D

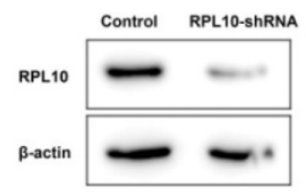

G

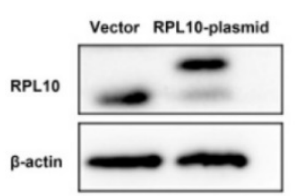

E

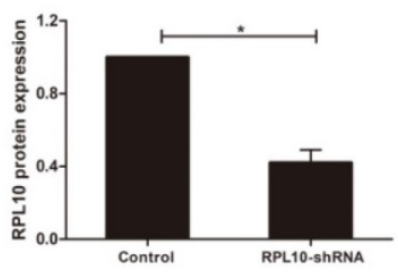

H

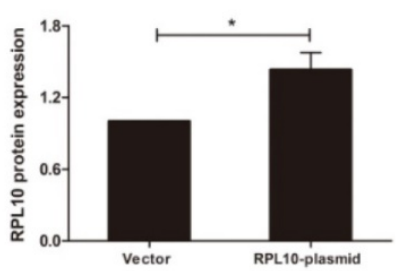

$c$

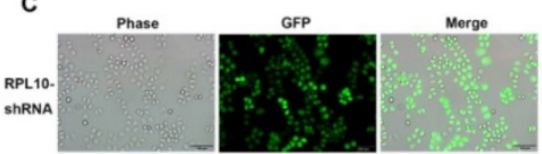

$\mathbf{F}$

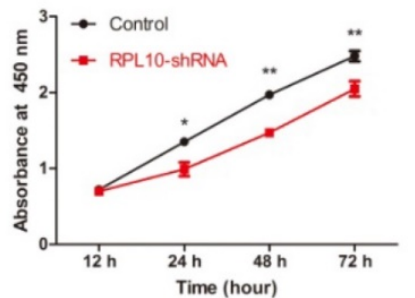

I

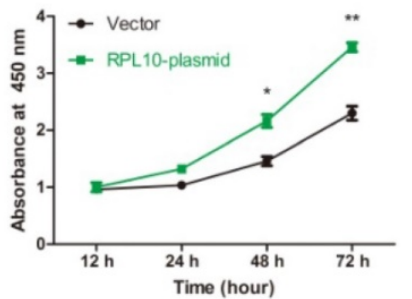

$\mathrm{EOC}$

cell

viability detecte

d by

WST-1

assay.

We

found a

signific

ant

decreas

e of cell

growth

in

RPL10-s

hRNA

expressi

ng cells

at 24,

48, and

$72 \mathrm{~h}$

post-see

ding

compar

ed with

control

cells

( $\mathrm{P}<0.05$;

Fig. 3F). control-siRNA; SI Homo-RPL10-339; S2 Homo-RPL10-388; S3 Homo-RPL10-723; RPLI0-shRNA RPL10-shRNA expressing cell; RPLI0-plasmid RPL10-plasmid expressing cell. 


\section{RPL10 overexpression increases ovarian cancer cell viability}

A gain-of-function approach was also used to evaluate the effect of RPL10 on OC cell viability. The overexpression of RPL10 protein after RPL10-plasmid lentivirus infection was confirmed by Western blotting (Fig. 3G and 3H). Overexpression of RPL10 affected ovarian cancer cell viability also detected by WST-1 assay. We found a significant increase of cell growth in RPL10-plasmid expressing cells at 48 and $72 \mathrm{~h}$ post-seeding compared with control cells $(\mathrm{P}<0.01$; Fig. 3I).

\section{RPL10 affects ovarian cancer cells migration and invasion}

To examine cell migration and invasion, a transwell assay was performed. The number of migrated cells was reduced in RPL10-shRNA expressing cells compared with control cells at $36 \mathrm{~h}$ after seeding. Similarly, the number of invaded RPL10-shRNA expressing cells was also decreased after knockdown of RPL10 at $48 \mathrm{~h}$ compared with control cells (Fig. 4A). We observed the number of migrated and invaded RPL10-plasmid expressing cells was increased at $36 \mathrm{~h}$ and $48 \mathrm{~h}$ compared with control cells, respectively (Fig. 4B). These data indicate that the suppression of RPL10 expression significantly inhibited cell migration and invasion, while the overexpression of RPL10 significantly increased cell migration and invasion.

\section{RPL10 influences cell cycle and apoptosis}

Flow cytometry was applied to evaluate the cell cycle and apoptosis. We found that RPL10 did not influence cell cycle (Fig. 5A-5D). The number of early apoptotic cells was increased in RPL10-shRNA cells (Fig. 5E and 5F), but decreased in RPL10-plasmid cells (Fig. 5G and 5H), compared with control cells.
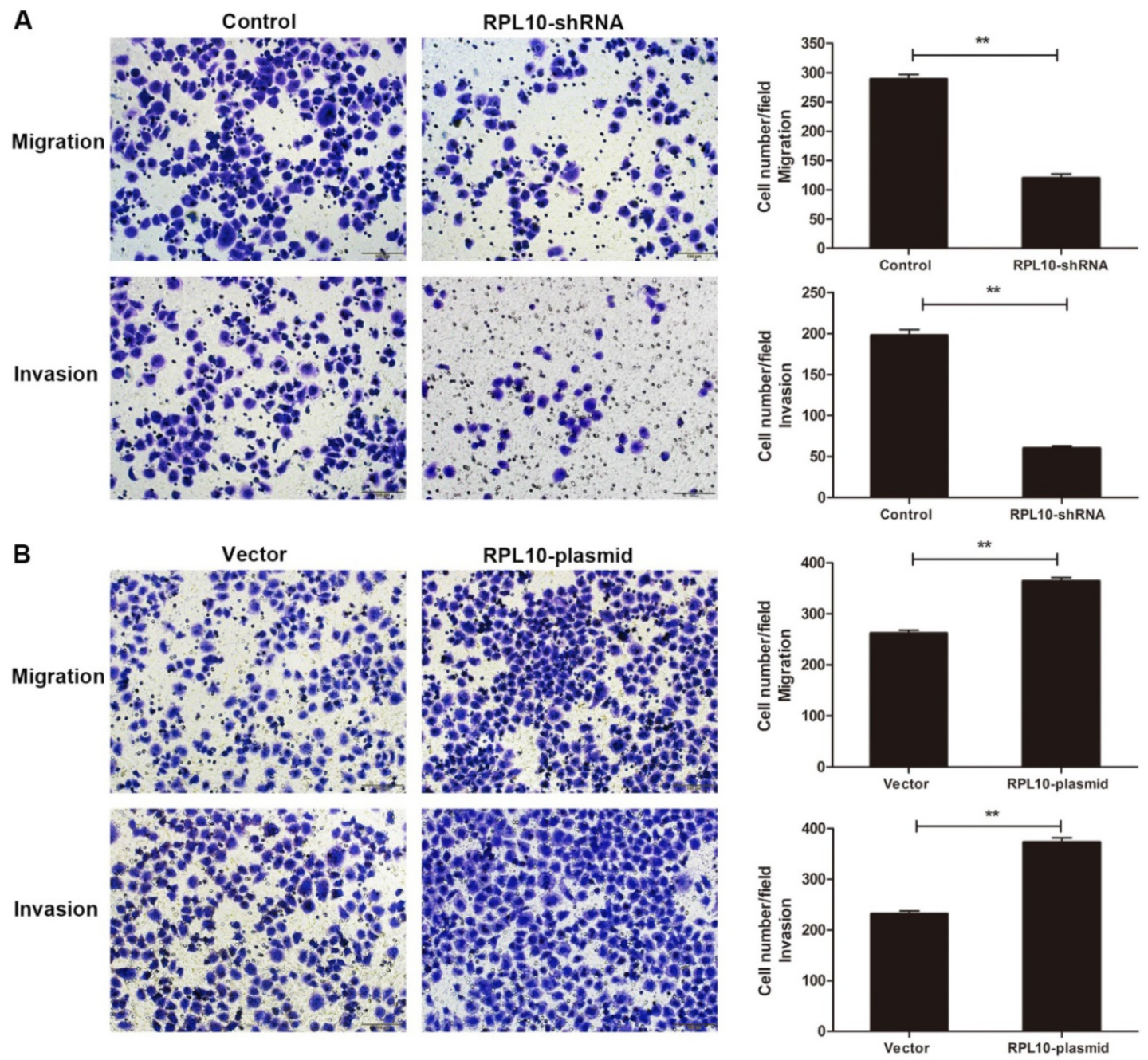

Figure 4. Effect of RPL10-shRNA and RPL10-plasmid on cell migration and invasion. (A) Cell migration and invasion of RPL10-shRNA in a transwell assay. (B) Cell migration and invasion of RPL10-plasmid in a transwell assay. Cell migration was measured after $36 \mathrm{~h}$ seeding and invasion was measured after $48 \mathrm{~h}$ seeding. Histogram shows the quantitative analysis of migrated and invaded cells from three random microscopic fields, respectively. At least three independent experiments were performed and a similar result was obtained. Original amplification, $\times 200$; scale bar, $100 \mu \mathrm{m}$. $* *, P<0.01$. 

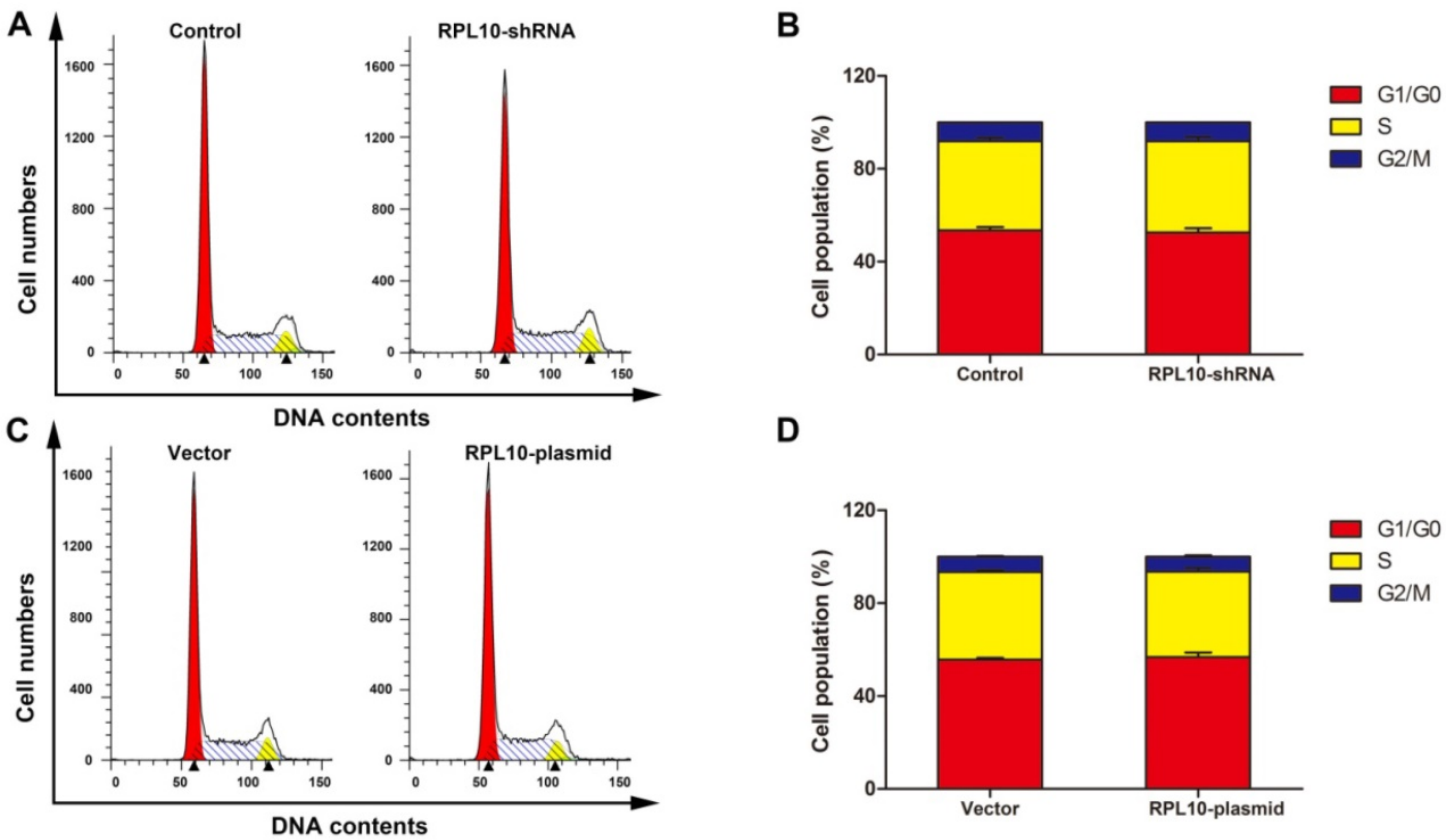

D
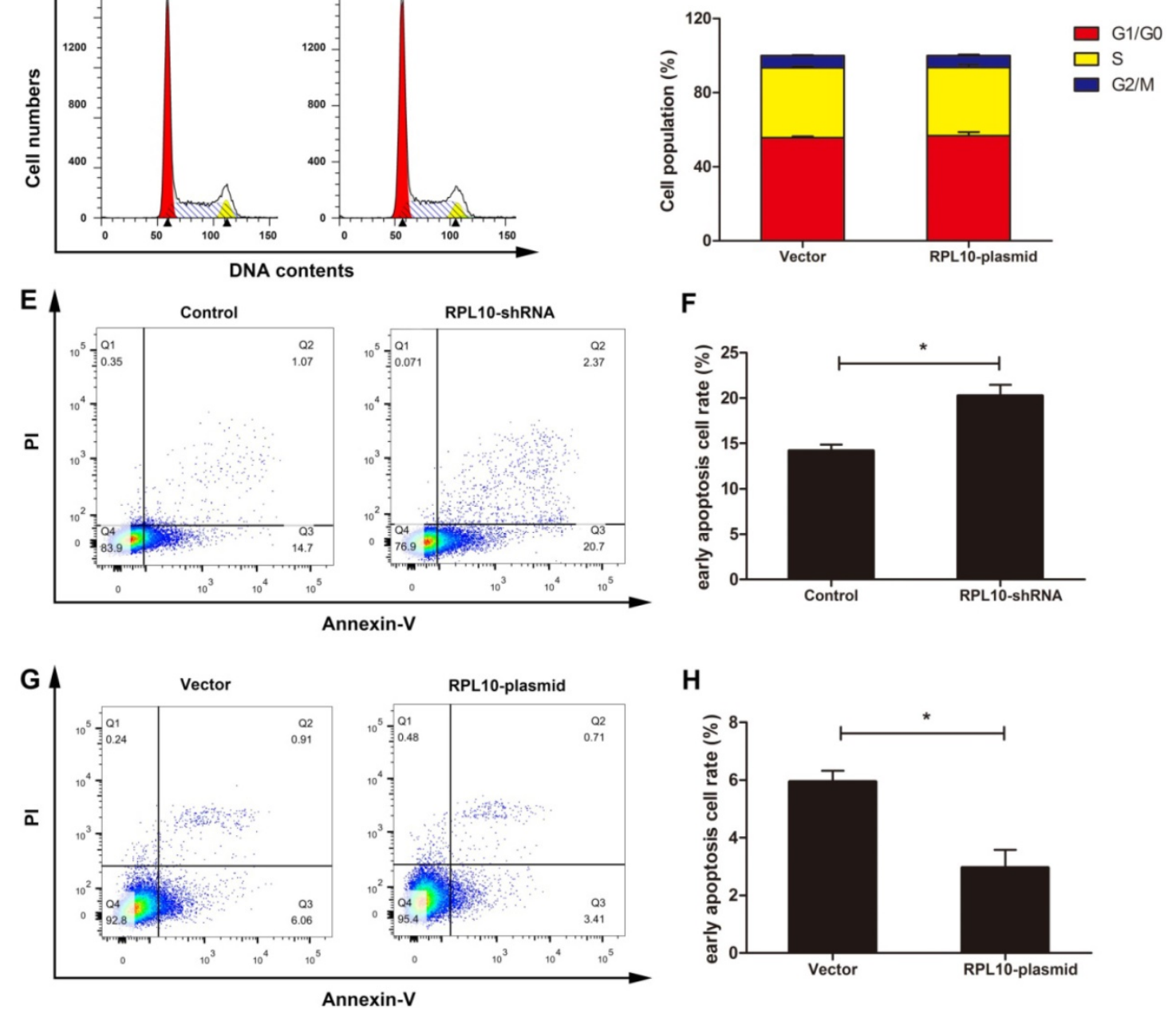

Figure 5. Effect of RPL10-shRNA and RPL10-plasmid on cell cycle and apoptosis. (A) Images of flow cytometry on cell cycle after RPL10-shRNA and control siRNA infection. (B) Histogram shows the percentage of the cell population in each phase of (A). (C) Images of flow cytometry on cell cycle after RPL10-plasmid and empty vector infection. (D) Histograms show the percentage of the cell population in each phase of (C). (E) The population of apoptotic cells of RPL10-shRNA and control detected by flow cytometry is shown. (F) Histogram shows the quantification of the population of early apoptotic cells. (G) The population of apoptotic cells of RPL10-plasmid and empty vector detected by flow cytometry is shown. $(\mathrm{H})$ Histogram shows the quantification of the population of early apoptotic cells. $\mathrm{n}=3$; *, $\mathrm{P}<0.05$; **, $\mathrm{P}<0.01$.

\section{RPL10 is regulated by miR-143-3p in OC cells}

MiR-143-3p mimics decreased RPL10 protein expression ( $\mathrm{P}<0.05$; Fig. $6 \mathrm{~A}$ and $6 \mathrm{~B})$, whereas miR-143-3p inhibitor (anti-miR-143) increased RPL10 protein expression $(\mathrm{P}<0.01$; Fig. $6 \mathrm{C}$ and $6 \mathrm{D})$, in OVCAR-3 cells. Furthermore, we found that the expression level of miR-143-3p was lower in
RPL10-shRNA-expression cell (Fig, 6E), but was high in RPL10 overexpressing cells (Fig, 6F), compared with their respective controls. These data suggest that there might be a feedback loop existed. However, using miRWalk 2.0 database [27], we did not find RPL10 as a potential target of miR-143-3p. 


\section{Discussion}

$\mathrm{OC}$ is one of the most invasive tumor diseases in postmenopausal women. It has very poor prognosis due to the hardness of detection at an early stage. Our current study showed the evidence of RPL10 overexpression in tissues of human OC. Moreover, the overexpression of RPL10 was also observed in EOC cell line. Using loss-of-function and gain-of-function approaches, we examined the biological functions of RPL10 in vitro on EOC cell growth, migration, invasion, and apoptosis, further demonstrating that RPL10 is a novel diagnostic marker and treatment target for OC.

To date, there are few studies on the role of RPL10 in tumorigenesis. RPL10 gene was originally isolated in Wilms' tumor [4]. RPL10 is expressed in a variety of embryonic and adult tissues and proved a downregulation of expression in adult kidney and heart. Previous data showed that the level of RPL10 expression is higher in rapidly dividing tissues than in the adult and differentiated tissues [28], suggesting that RPL10 may influence development and differentiation. RPL10 is differentially expressed during vertebrate endochondral bone development [29]. Mutations of RPL10 gene were closely predisposed to T-cell acute lymphoblastic leukemia [30]. The expression of RPL10 protein is elevated at the late stage of prostate cancer development, facilitating more aggressive phenotype [7]. RPL10 has been shown to be associated with premature ovarian failure [31]. The expression level is higher in mature ovary than in immature ovary of Penaeus monodon [16]. High frequencies of loss of heterozygosity and microsatellite instability at the Xq28 and of the A/G heterozygosity at the 605th nucleotides of the RPL10 gene may be associated with OC [32]. Our study showed that RPL10 was overexpressed in OC cell line and OC tissues, including serous, mucinous, endometrioid, transitional cell, and clear cell carcinoma. These results are consistent with data extracted from the microarray datasets of Bonome and TCGA in Oncomine databases that RPL10 mRNA expression is higher in OC than normal ovary, indicating that RPL10 may play a role in OC development.

It has been shown that RPL10 is functional in cell signaling and development [33]. A previous study indicated that RPL10 involved in different intracellular processes, such as cell stability, division, proliferation, migration, and differentiation [6]. In the current study, we demonstrated that suppression of RPL10 gene induced cell apoptosis and inhibited cell migration and invasion of OC cells. On the contrary, overexpressed RPL10 reduced OC cell apoptosis and increased cell migration and invasion. These data indicate that RPL10 may be a potential target for OC treatment. In the current study, we did not find the correlation of RPL10 protein expression with the clinicopathological features, such as age, histological types, lymph node metastasis, and clinical stage. This is most likely due to the small sample size of patients with malignant tumors (total 31 cases). Thus, an increase in sample number must be considered in the future study.

RPL10 is a zinc-binding regulatory protein and interacts c-Jun, which is regulated by zinc ions and phosphorylation [34]. RPL10 is highly homologous to the Jun-binding protein (Jif-1) and forms a complex with c-Jun

Figure 6. Regulation of RPL10 expression by miR-143-3p in OVCAR-3 cells. (A) Expression of RPL10 protein in the negative control (CTL) and miR-143-3p (miR-/43) transfected cells for $72 \mathrm{~h}$ detected by Western blot. (B) Histogram shows the semi-quantitative analysis after densitometry on the gels of (A). (C) Expression of RPL10 protein in the negative control (NC) and anti-miR-143-3p ( 143 -inhibitor) cells for $72 \mathrm{~h}$ detected by Western blot. (D) Histogram shows the semi-quantitative analysis after densitometry on the gels of $(C)$. (E) Expression of miR-143-3p in negative control and RPL10-shRNA-expressing cells detected by qRT-PCR. (F) Expression of miR-143-3p in empty vector control and RPL10-plasmid transfected cells detected by $\mathrm{qRT}-\mathrm{PCR}$. $\mathrm{n}=3 ;{ }^{*}, \mathrm{P}<0.05 ; * *, \mathrm{P}<0.01$. 
and represses its ability to trans-activation gene expression by inhibiting the binding of c-Jun to DNA [35]. RPL10 serves as a negative regulator of c-Jun transcription factor and interacts presenilin 1 in human cortical neurons [36] and takes part in signal transduction through association to c-Yes [6]. It has been shown that the c-Jun signaling pathway is involved in cellular proliferation, migration, and invasion [37, 38]. Furthermore, RPL10 specifically binds to p65 or IKK $\gamma$, influencing the NF-kB pathway to synergistically determine the fate of various cellular processes [39]. Thus, we believe that the effect of overexpressed RPL10 on OC cell behavior may be through the c-Jun signaling and/or NF-kB pathways during the development of OC.

Recent studies have shown that miR-143-3p is involved in the development of many cancers, such as breast, cervical, prostate, colorectal, bladder, and ovarian cancers [19, 40-45]. Indeed, we confirmed that miRNA-143-3p regulates RPL10 expression in OC, which is consistent with the previous study that the expression level of miR-143 is downregulated in EOC tissues and cell lines [20]. Using gain-of-function and loss-of-function approaches we demonstrated that RPL10 is a downstream molecule of miR-143-3p and there may be a feedback loop existed. After checking miRWalk 2.0 database [27], we did not find a relationship between RPL10 and miR-143-3p. Therefore, RPL10 may be an indirect target of miR-143-3p and there is another mechanism in the regulation of RPL10 expression by miR-143-3p.

In summary, the current study has illustrated that RPL10 is upregulated in human ovarian malignant tumors. The expression of RPL10 is regulated by miR-130b-3p. Suppression of RPL10 inhibits EOC cell viability, migration, and invasion and induces apoptosis, whereas overexpression of RPL10 increases EOC cell viability, migration, and invasion and reduces apoptosis. These data implicate that RPL10 has a biological function on OC cell behavior and may be a tissue biomarker and a novel therapeutic target of OC.

\section{Abbreviations}

EOC: epithelial ovarian cancer; IHC: immunohistochemistry; RPL10： Ribosomal protein L10.

\section{Acknowledgements}

This work was supported by grants from National Natural Science Foundation of China (81272880), Science and Technology Commission of Shanghai Municipality (124119b1300), Natural Science Foundation of Shanghai (17ZR1404100) and Shanghai Municipal Commission of Health and Family Planning (201640287) to G. Xu and Science and
Technology Commission of Jinshan District (2014-3-22) to J. Shi.

\section{Authors' contributions}

J Shi and L Zhang performed cell culture, sample collection, Western blot, the data analysis, figure generation, and manuscript drafting. L Zhang and J Zhang conducted the bioinformatics analysis. D Zhou and J Zhang participated in tissue protein extraction and performed Western blot analysis. Q Lin and W Guan conducted siRNA experiments and analyzed data. J Zhang and W Ren performed immunohistochemistry assays and pathologic examination. GXu contributed to the data analysis, the generation of figures and the writing of the manuscript. All authors read and approved the final manuscript.

\section{Competing Interests}

The authors have declared that no competing interest exists.

\section{References}

1. Farmer AA, Loftus TM, Mills AA, Sato KY, Neill JD, Tron T, et al. Extreme evolutionary conservation of $\mathrm{QM}$, a novel c-Jun associated transcription factor. Human Molecular Genetics. 1994; 3: 723-8.

2. Eisinger DP, Dick FA, Trumpower BL. Qsr1p, a 60 S ribosomal subunit protein, is required for joining of $40 \mathrm{~S}$ and $60 \mathrm{~S}$ subunits. Molecular and Cellular Biology. 1997; 17: 5136-45.

3. Loftus TM, Nguyen YH, Stanbridge EJ. The QM protein associates with ribosomes in the rough endoplasmic reticulum. Biochemistry. 1997; 36: 8224-30.

4. Dowdy SF, Lai KM, Weissman BE, Matsui Y, Hogan BL, Stanbridge EJ. The isolation and characterization of a novel cDNA demonstrating an altered mRNA level in nontumorigenic Wilms' microcell hybrid cells. Nucleic Acids Research. 1991; 19: 5763-9.

5. Chan YL, Diaz JJ, Denoroy L, Madjar JJ, Wool IG. The primary structure of rat ribosomal protein L10: relationship to a Jun-binding protein and to a putative Wilms' tumor suppressor. Biochemical and Biophysical Research Communications. 1996; 225: 952-6.

6. Oh HS, Kwon $\mathrm{H}$, Sun $\mathrm{SK}$, Yang $\mathrm{CH}$. QM, a putative tumor suppressor, regulates proto-oncogene c-yes. J Biol Chem. 2002; 277: 36489-98.

7. Altinok G, Powell IJ, Che M, Hormont K, Sarkar FH, Sakr WA, et al. Reduction of QM protein expression correlates with tumor grade in prostatic adenocarcinoma. Prostate Cancer and Prostatic Diseases. 2006; 9: 77-82.

8. Klauck SM, Felder B, Kolb-Kokocinski A, Schuster C, Chiocchetti A, Schupp I, et al. Mutations in the ribosomal protein gene RPL10 suggest a novel modulating disease mechanism for autism. Molecular Psychiatry. 2006; 11: 1073-84.

9. Chiocchetti A, Pakalapati G, Duketis E, Wiemann S, Poustka A, Poustka F, et al. Mutation and expression analyses of the ribosomal protein gene RPL10 in an extended German sample of patients with autism spectrum disorder. American Journal of Medical Genetics Part A. 2011; 155A: 1472-5.

10. Brooks SS, Wall AL, Golzio C, Reid DW, Kondyles A, Willer JR, et al. A novel ribosomopathy caused by dysfunction of RPL10 disrupts neurodevelopment and causes X-linked microcephaly in humans. Genetics. 2014; 198: 723-33.

11. Wen Y, Shao JZ, Pan XX, Xiang LX. Molecular cloning, characterization and expression analysis of QM gene from grass carp (Ctenopharyngodon idellus) homologous to Wilms' tumor suppressor. Comparative Biochemistry and Physiology Part B, Biochemistry \& Molecular Biology. 2005; 141: 356-65.

12. Rocha CS, Santos AA, Machado JP, Fontes EP. The ribosomal protein L10/QM-like protein is a component of the NIK-mediated antiviral signaling. Virology. 2008; 380: 165-9.

13. Oh C, De Zoysa M, Nikapitiya C, Whang I, Kim YC, Kang DH, et al. Tumor suppressor QM-like gene from disk abalone (Haliotis discus discus): molecular characterization and transcriptional analysis upon immune challenge. Fish \& Shellfish Immunology. 2010; 29: 494-500.

14. Chen X, Su YQ, Wang J, Liu M, Niu SF, Zhong SP, et al. Isolation and identification of the immune-relevant ribosomal protein L10 (RPL10/QM-like gene) from the large yellow croaker Pseudosciaena crocea (Pisces: Sciaenidae). Genetics and Molecular Research: GMR. 2012; 11: 3755-65.

15. Xu J, Wu S, Zhang X. Novel function of QM protein of shrimp (Penaeus japonicus) in regulation of phenol oxidase activity by interaction with hemocyanin. Cellular Physiology and Biochemistry: international journal of 
experimental cellular physiology, biochemistry, and pharmacology. 2008; 21: 473-80.

16. Zhou F, Jiang S, Huang J, Qiu L, Zhang D, Su T. Molecular analysis of the QM gene from Penaeus monodon and its expression on the different ovarian stages of development. Molecular Biology Reports. 2011; 38: 1921-7.

17. Banno K, Yanokura M, Iida M, Adachi M, Nakamura K, Nogami Y, et al. Application of microRNA in diagnosis and treatment of ovarian cancer. BioMed Research International. 2014; 2014: 232817.

18. Logan M, Hawkins SM. Role of microRNAs in cancers of the female reproductive tract: insights from recent clinical and experimental discovery studies. Clinical Science. 2015; 128: 153-80.

19. Zhang H, Li W. Dysregulation of micro-143-3p and BALBP1 contributes to the pathogenesis of the development of ovarian carcinoma. Oncol Rep. 2016; 36: 3605-10.

20. Wang L, He J, Xu H, Xu L, Li N. MiR-143 targets CTGF and exerts tumor-suppressing functions in epithelial ovarian cancer. Am J Transl Res. 2016; 8: 2716-26.

21. Jayson GC, Kohn EC, Kitchener HC, Ledermann JA. Ovarian cancer. Lancet. 2014; 384: 1376-88.

22. Wang X, Gui L, Zhang Y, Zhang J, Shi J, Xu G. Cystatin B is a progression marker of human epithelial ovarian tumors mediated by the TGF-beta signaling pathway. Int J Oncol. 2014; 44: 1099-106.

23. Sun W, Gui L, Zuo X, Zhang L, Zhou D, Duan X, et al. Human epithelial-type ovarian tumour marker beta-2-microglobulin is regulated by the TGF-beta signaling pathway. Journal of Translational Medicine. 2016; 14: 75.

24. Zhou D, Zhang L, Sun W, Guan W, Lin Q, Ren W, et al. Cytidine monophosphate kinase is inhibited by the TGF-beta signalling pathway through the upregulation of miR-130b-3p in human epithelial ovarian cancer. Cellular Signalling. 2017

25. Zhang L, Zhou D, Guan W, Ren W, Sun W, Shi J, et al. Pyridoxine 5'-phosphate oxidase is a novel therapeutic target and regulated by the TGF-beta signalling pathway in epithelial ovarian cancer. Cell Death \& Disease. 2017; 8: 3214.

26. Lv X, Zhang L, Zhu Y, Said HM, Shi J, Xu G. Regulative Effect of Nampt on Tumor Progression and Cell Viability in Human Colorectal Cancer. Journal of Cancer. 2015; 6: 849-58.

27. Dweep H, Gretz N. miRWalk2.0: a comprehensive atlas of microRNA-target interactions. Nature Methods. 2015; 12: 697.

28. Hwang JS, Goo TW, Yun EY, Lee JH, Kang SW, Kim KY, et al. Tissue-/stage-dependent expression of a cloned Bombyx mandarina QM homologue. Biomolecular Engineering. 2000; 16: 211-5.

29. Green $\mathrm{H}$, Canfield AE, Hillarby MC, Grant ME, Boot-Handford RP, Freemont $\mathrm{AJ}$, et al. The ribosomal protein $\mathrm{QM}$ is expressed differentially during vertebrate endochondral bone development. Journal of Bone and Mineral Research: the official journal of the American Society for Bone and Mineral Research. 2000; 15: 1066-75.

30. De Keersmaecker K, Atak ZK, Li N, Vicente C, Patchett S, Girardi T, et al. Exome sequencing identifies mutation in CNOT3 and ribosomal genes RPL5 and RPL10 in T-cell acute lymphoblastic leukemia. Nature Genetics. 2013; 45: $186-90$.

31. Massad-Costa AM, da Silva ID, Affonso R, Soares JM, Jr., Nunes MG, de Lima GR, et al. Gene analysis in patients with premature ovarian failure or gonadal dysgenesis: a preliminary study. Maturitas. 2007; 57: 399-404.

32. Shen XJ, Ali-Fehmi R, Weng CR, Sarkar FH, Grignon D, Liao DJ. Loss of heterozygosity and microsatellite instability at the $\mathrm{Xq} 28$ and the $\mathrm{A} / \mathrm{G}$ heterozygosity of the QM gene are associated with ovarian cancer. Cancer Biology \& Therapy. 2006; 5: 523-8.

33. Tron T, Yang M, Dick FA, Schmitt ME, Trumpower BL. QSR1, an essential yeast gene with a genetic relationship to a subunit of the mitochondrial cytochrome bc1 complex, is homologous to a gene implicated in eukaryotic cell differentiation. The Journal of Biological Chemistry. 1995; 270: 9961-70.

34. Inada $\mathrm{H}$, Mukai J, Matsushima S, Tanaka T. QM is a novel zinc-binding transcription regulatory protein: its binding to c-Jun is regulated by zinc ions and phosphorylation by protein kinase C. Biochemical and Biophysical Research Communications. 1997; 230: 331-4.

35. Monteclaro FS, Vogt PK. A Jun-binding protein related to a putative tumor suppressor. Proceedings of the National Academy of Sciences of the United States of America. 1993; 90: 6726-30.

36. Imafuku I, Masaki T, Waragai M, Takeuchi S, Kawabata M, Hirai S, et al. Presenilin 1 suppresses the function of c-Jun homodimers via interaction with QM/Jif-1. The Journal of Cell Biology. 1999; 147: 121-34.

37. Watanabe T, Hiasa Y, Tokumoto Y, Hirooka M, Abe M, Ikeda Y, et al. Protein kinase $\mathrm{R}$ modulates c-Fos and c-Jun signaling to promote proliferation of hepatocellular carcinoma with hepatitis C virus infection. PLoS One. 2013; 8: e67750.

38. Jiao X, Katiyar S, Liu M, Mueller SC, Lisanti MP, Li A, et al. Disruption of c-Jun reduces cellular migration and invasion through inhibition of c-Src and hyperactivation of ROCK II kinase. Molecular Biology of the Cell. 2008; 19: 1378-90.

39. Shi $C$, Wang $Y$, Guo $Y$, Chen $Y$, Liu N. Cooperative down-regulation of ribosomal protein L10 and NF-kappaB signaling pathway is responsible for the anti-proliferative effects by DMAPT in pancreatic cancer cells. Oncotarget. 2017; 8: 35009-18.

40. Li D, Hu J, Song $\mathrm{H}, \mathrm{Xu} \mathrm{H}, \mathrm{Wu} \mathrm{C}$, Zhao B, et al. miR-143-3p targeting LIM domain kinase 1 suppresses the progression of triple-negative breast cancer cells. American Journal of Translational Research. 2017; 9: 2276-85.
41. Jin $\mathrm{X}$, Chen $\mathrm{X}, \mathrm{Hu} \mathrm{Y}$, Ying $\mathrm{F}$, Zou R, Lin F, et al. LncRNA-TCONS 00026907 is involved in the progression and prognosis of cervical cancer through inhibiting miR-143-5p. Cancer Medicine. 2017.

42. Huang FT, Chen WY, Gu ZQ, Zhuang YY, Li CQ, Wang LY, et al. The novel long intergenic noncoding RNA UCC promotes colorectal cancer progression by sponging miR-143. Cell Death \& Disease. 2017; 8: e2778.

43. Cao H, Yu H, Feng Y, Chen L, Liang F. Curcumin inhibits prostate cancer by targeting PGK1 in the FOXD3/miR-143 axis. Cancer Chemotherapy and Pharmacology. 2017; 79: 985-94

44. Wang $\mathrm{H}$, Li O, Niu X, Wang G, Zheng S, Fu G, et al. miR-143 inhibits bladder cancer cell proliferation and enhances their sensitivity to gemcitabine by repressing IGF-1R signaling. Oncology Letters. 2017; 13: 435-40.

45. Ma Z, Luo Y, Qiu M. miR-143 Induces the Apoptosis of Prostate Cancer LNCap Cells by Suppressing Bcl-2 Expression. Medical Science Monitor: international medical journal of experimental and clinical research. 2017; 23: 359-65. 